\title{
Study on Evolution and Interaction of Service Industry Agglomeration and Efficiency of Hebei Province China
}

\author{
Jianguo Liu (iD) and Mingyu Zhao \\ Tourism College of Beijing Union University, Beijing 100101, China \\ Correspondence should be addressed to Jianguo Liu; liujianguo009@163.com
}

Received 10 April 2020; Revised 6 May 2020; Accepted 20 May 2020; Published 30 July 2020

Guest Editor: Jun Yang

Copyright (C) 2020 Jianguo Liu and Mingyu Zhao. This is an open access article distributed under the Creative Commons Attribution License, which permits unrestricted use, distribution, and reproduction in any medium, provided the original work is properly cited.

\begin{abstract}
Using data from 2008 to 2017 regarding the service sector in 11 cities of the Hebei Province, this study measures the degree of agglomeration and efficiency of service subsectors, analyzes their spatiotemporal evolution, and discusses the interactive relationship between them using panel vector autoregressive (PVAR) models and GMM dynamic panel model. The findings are summarized as follows: (1) from 2008 to 2017, service subsectors in Hebei's cities have a high degree of agglomeration and benefit significantly from specialization; (2) the service in Hebei's cities is severely inefficient (i.e., efficiency loss is grave). The empirical results of PVAR models reveal that service sector agglomeration is primarily reliant on its own development momentum and while that can improve technical efficiency and pure technical efficiency, it can also inhibit technical change efficiency. The variance decomposition results reveal that service sector efficiency is influenced more significantly by itself than by service sector agglomeration. With the passage of time, the self-influence of efficiency decreases and the influence of service sector agglomeration on efficiency increases.
\end{abstract}

\section{Introduction}

Over 40 years since its reform and opening-up, China's economy has grown rapidly owing to multiple advantages such as low-cost labor resources and high-intensity capital input. Today, China's economic development has entered a new stage: its demographic dividend is disappearing, and ecological and environmental problems are increasingly severe. In this context, the traditional rapid economic growth model, which relies heavily on factor input, is difficult to sustain. As pointed out in the report of the $19^{\text {th }}$ National Congress of the Communist Party of China (CPC), China is entering the critical stage of needing to transform its mode of development, optimize its economic structure, change its impetus of growth, emphasize quality, efficiency. and impetus innovation, and improve total factor productivity (TFP). Technical Change and the Aggregate Production Function was the first study of TFP. It showed that, when the contributions of increases in capital and labor are excluded from total growth, the residual growth is the contribution from technical change and, therefore, economic growth can be promoted by technical change while factor input remains unchanged (Solow, 1957) [1]. Subsequently, both Chinese and international scholars have studied TFP [2]. The research content mainly includes the influencing factors of total factor productivity [3-5] and the spatial and temporal evolution characteristics of total factor productivity of regional economy [6] or industry [7]. In order to alleviate the contradiction between the development of and ecological environmental protection, the concept of green development has become increasingly popular, and scholars have increasingly begun to pay attention to the temporal and spatial evolution of green total factor productivity and its influencing factors [8-10]. In recent years, there have been frequent studies on industry agglomeration and efficiency as the effect of industrial agglomeration on economic growth becomes increasingly significant [11]. Studies also show that there is an inverted "U"-shaped relationship between industry agglomeration and industry efficiency [12]. On one hand, concentrated geographical distribution of similar 
enterprises can promote infrastructure sharing and information exchange, thereby creating additional benefits of specialization including: facilitating the spread of inferred knowledge, speedier labor matching, and stimulating enterprises' vitality and creativity. This is the agglomeration effect, which serves to improve economic efficiency $[13,14]$. On the other hand, the increasing and excessive agglomeration of enterprises creates various problems (e.g., land price increases, innovation simulation, and fierce competition), which leads to a rise in production costs, reduces motivation to innovate, and has a crowding effect, all of which inhibit economic efficiency $[15,16]$. To improve the industry efficiency, it is therefore important to compare the agglomeration effect to the crowding effect. The Williamson hypothesis argues the following: (1) at an early stage of economic development, the agglomeration effect outweighs the crowding effect: in short, industry agglomeration serves to improve the industry efficiency; but (2) when the level of economic development reaches a certain inflection point, the crowding effect outweighs the agglomeration effect, so that spatial industry agglomeration impedes the industry efficiency [17]. To summarize, most of the existing studies on industry agglomeration and efficiency select different spatial scales and different industries to empirically test the Williamson hypothesis, and their conclusions vary from study to study [18-21]. Industrial agglomeration not only affects economic growth but also impacts pollutant emissions. Some studies have shown that industrial agglomeration can effectively reduce water pollutant emissions. This positive effect is more significant in small cities [22].

With the pervasiveness of economic globalization and increased industrialization, knowledge, information, technology, and human capital have become increasingly significant contributors to economic growth, and services are assuming greater importance at the expense of industry [23]. A developed service sector not only gives an impetus to regional competitiveness but also is an important indicator of the development potential of a regional economy [24]. The service sector is mainly characterized by the application of modern technologies, new types of business models, and new ideas, which provide society with high-value-added, sophisticated, knowledge-based producer and consumer services. Today, the service sector plays an increasingly important role in offering employment, improving efficiency of the manufacturing sector, and optimizing and upgrading industrial infrastructure. Most existing studies pertaining to the service sector concentrate on producer services (an important component of the sector) $[25,26]$ and mainly discuss the relationship between the agglomeration of producer services and manufacturing [27-29]. They examine issues like the measurement of service sector agglomeration [30], agglomeration patterns [31-33], and their influence on economic development [34-36]. Their spatial scales include county, city, and city cluster scales, most of which are areas with a highly developed economy [37, 38].

In summary, many studies have been conducted to examine industry agglomeration and the service sector. However, the relationship between service sector agglomeration and efficiency has not yet been examined in detail.
Therefore, this study discusses the evolutionary pathways of agglomeration and the efficiency of Hebei's service sector as well as the relationship between them. It is aspired that this study's findings will provide theoretical support for the development of Hebei's modern service sector.

\section{Study Area, Methodology, and Data}

2.1. Study Area. Hebei is an important component of the Beijing-Tianjin-Hebei city cluster and is an economically developed and densely populated region of China. Hebei administers 11 cities (comprising Shijiazhuang, Chengde, Zhangjiakou, Qinhuangdao, Tangshan, Langfang, Baoding, Cangzhou, Hengshui, Xingtai, and Handan). As of the end of 2019, the permanent population of Hebei Province is 7759.197 million and GDP of 3,596 billion yuan, of which the tertiary sector contributed 1,504 billion yuan, or $41.8 \%$. The Beijing-Tianjin-Hebei Urban Agglomeration is an important growth center in China. However, as a part of the Beijing-Tianjin-Hebei Urban Agglomeration, Hebei Province has a large gap with both Beijing and Tianjin in its development. Undoubtedly, the development of Hebei is key to determine the development of the Beijing-Tianjin-Hebei metropolis in the future. From the perspective of the service industry's development, Beijing's service industry accounts for a high proportion of the GDP, almost $80 \%$, whereas Hebei's service industry accounts for a relatively low proportion. Broadly, the development of the service industry is an important indicator that helps determine the level of urban development in a particular region. Taking Hebei Province as an example, this paper reveals the temporal and spatial evolution law and characteristics of service industry agglomeration and efficiency and discusses the interaction between them, which has certain guiding significance for further promoting the modernization level of Hebei Province and enhancing the international competitiveness of the Beijing, Tianjin, and Hebei metropolises.

\subsection{Methodology}

2.2.1. Measuring the Agglomeration Level of Service Industry by Location Quotient (LQ). The degree of industry agglomeration is usually measured by the $L Q$, Herfindahl index, or $E G$ index. Considering the advantages and disadvantages of different methods, the purpose of this study and the availability of data, the LQ method is used to measure the agglomeration characteristics of the regional modern service sector. The $L Q$ is measured by the following equation:

$$
L Q_{i j}=\frac{L_{i j} / L_{i}}{L_{j} / L},
$$

where $L_{i j}$ denotes the employee population in the service industry of City $j, L_{i}$ denotes the total employee population of City $j, L_{j}$ denotes the total employee population in the service sector of all cities, $L$ denotes the total employee population of all cities, and $L Q_{i j}$ denotes the $L Q$ index. The higher the $L Q_{i j}$ value, the greater the degree of specialization [39]. 
2.2.2. Measuring Service Industry Efficiency by the DEAMalmquist Index. Data envelopment analysis (DEA) is widely applied for efficiency measurement because it has no specific requirements for the form of a production function and requires no setting of producers' optimal behaviors. Because the input of the service sector is a controlled variable and the output of the sector is uncontrollable, the service sector efficiency is measured using a $B C C$ model with variable returns to the scale. Assume that there are $n$ decision-making units $\left(D M U_{j}\right), m$ input variables (expressed as $\left.x_{1 j}, \quad x_{2 j}, \ldots, x_{\mathrm{m} j}\right), s$ output variables (expressed as $y_{1 j}$, $y_{2 j}, \ldots, y_{s j}$ ), and the efficiency evaluation index for each $D M U$ is $\theta$. Its calculation equation is as follows:

$$
\left\{\begin{array}{l}
\min \quad \theta \\
\text { s.t. } \quad \sum_{i=1}^{n} \lambda_{j} x_{j \leq \theta x_{0}}, \\
\sum_{j=1}^{n} \lambda_{i} y_{i} \geq y_{0}, \\
\sum \lambda_{i}=1 .
\end{array}\right.
$$

TFP can be broken down into technical efficiency (TEC) and technical change efficiency (TCH) [6]. TEC is greatest when input use is minimized for a constant output or when output is maximized for a constant input [40]; $\mathrm{TCH}$, on the other hand, reflects the contribution of independent innovation. TEC can be further expressed as the product of pure technical efficiency (PEC) and scale efficiency (SEC). PEC reflects the contribution of technology to factor utilization, and SEC is the ratio of input to output [41]. Formally, TFP $=\mathrm{PEC} \times \mathrm{SEC} \times \mathrm{TCH}$. If TFP and its indices are all greater than 1 , the efficiency is effective; otherwise, there is efficiency loss [42].

According to the requirements of the input and output indices in the DEA-Malmquist index model, capital and labor are chosen as input factors, which are, respectively, denoted by the capital stock of the tertiary sector and the number of employees in the tertiary sector. The value added by the tertiary industry is used as an output measure. To ensure rationality and consistency of data, the value added by the tertiary sector is converted into comparable prices of the base period (2008), and the capital stock of the tertiary sector is calculated using the perpetual inventory method. It is calculated as follows:

$$
K_{i t}=I_{i t}-(1-\delta) K_{i t}-1,
$$

where, $K_{i t}$ and $K_{i t-1}$ denote the capital stock of the tertiary industry in region $i$ in the $t$-th year and $(t-1)$-th year, respectively, and $I_{i t}$ denotes the fixed investment in the base period (2008) (note: the rate of depreciation $(\delta)$ value used here is $6 \%$, in accordance with the previous studies); the initial capital stock is equal to the fixed investment in the base period, divided by $10 \%$ [43].

2.3. Data Source and Processing. In accordance with Industrial Classification for National Economic Activities (GB/ T4754-2002), the tertiary sector is classified into 14 specific subsectors: (1) transport, warehousing, and postal activities; (2) retail and wholesale; (3) accommodation and catering; (4) finance; (5) scientific research, technical services, and geological survey; (6) water conservancy, environment, and public facility management; (7) residential services and other services; (8) education; (9) health, social security, and social welfare; (10) culture, sports, and entertainment; (11) public administration and social organizations; and (12) international organizations. For consistency, this study-spanning the period from 2008 to 2017-uses data from China City Statistical Yearbook (2009-2018), China Statistical Yearbook (2009-2018), Hebei Economic Yearbook (2009-2018), and statistical bulletins of Hebei's prefecture-level cities (2009-2018). The specific data used includes the number of employees in the tertiary industry, the total number of employees, the capital stock of the tertiary industry, and the added value of the output value of the tertiary industry.

\section{Spatiotemporal Evolution Characteristics of Agglomeration and Efficiency of Hebei's Service Industry}

3.1. Spatiotemporal Evolution Characteristics of Service Industry Agglomeration. The $L Q$ is used to measure the degree of agglomeration of the service sector in Hebei's 11 cities from 2008 to 2017 (as shown in Figure 1). The results of the measurement show that services in Hebei's cities are highly specialized, and the $L Q$ values of most cities are greater than 1 , though with some spatial variation and fluctuation. From 2008 to 2017, the 11 cities can be ranked by their average $L Q$ values (in ascending order) as follows: Hengshui, Chengde, Zhangjiakou, Shijiazhuang, Cangzhou, Qinhuangdao, Xingtai, Langfang, Baoding, Handan, and Tangshan. This indicates that cities with the highest degree of service industry agglomeration are mainly distributed in northern and south-central Hebei. The $L Q$ values of most cities show a fluctuating trend. The $L Q$ values of six cities (Shijiazhuang, Chengde, Tangshan, Langfang, Hengshui, and Xingtai) show a $\mathrm{V}$-shaped fluctuation trend (that is, they decline at first and then rise); the $L Q$ values of four cities (Zhangjiakou, Qinhuangdao, Baoding, and Handan) show a W-shaped trend (they decline, rise, then decline, and rise again); and the $L Q$ values of Cangzhou show an $\mathrm{N}$-shaped fluctuation trend (rise, then decline, and then a rise again). From 2008 to 2018, the $L Q$ values of eight cities (Shijiazhuang, Chengde, Qinhuangdao, Langfang, Baoding, Hengshui, Xingtai, and Handan) decline by more than 0.3 , whereas the $L Q$ values of three cities (Zhangjiakou, Tangshan, and Cangzhou) fluctuate marginally. In 2017, the $L Q$ values of all 11 cities are greater than 1. From 2008 to 2017, while the degree of service sector agglomeration in Hebei shows some spatial variation and regional differences, Hebei's service sector is highly specialized overall. This is largely a result of the attention given to the service sector by the Hebei Provincial People's Government. In 2009, the Hebei Provincial People's Government promulgated Some Policy Measures on Promoting the Development of Service Industry in the Whole Province, deciding to implement tax concessions and fee reduction 


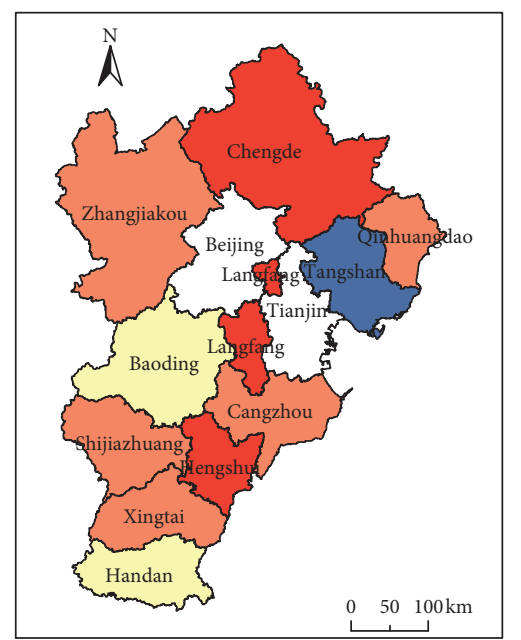

LQ (2008)

$\square 0.838 \sim 1.330$ $\square 1.331 \sim 1.565$ $\square 1.566 \sim 1.752$

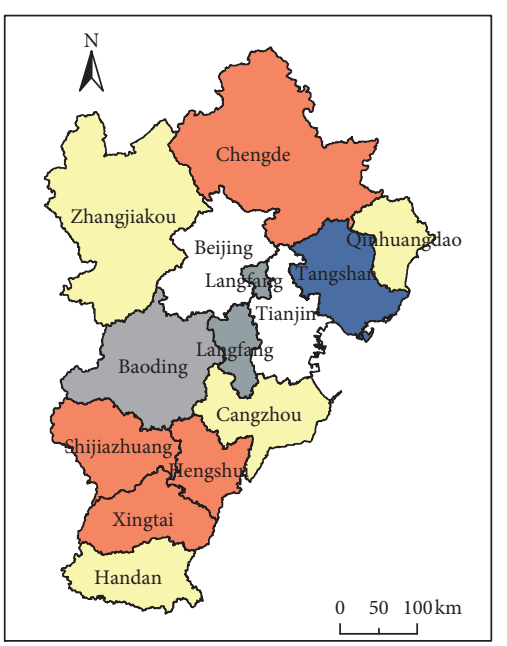

LQ (2011)

$\square 0.838 \sim 1.330$

$\square 1.331 \sim 1.565$ $\square 1.566 \sim 1.752$ (a)

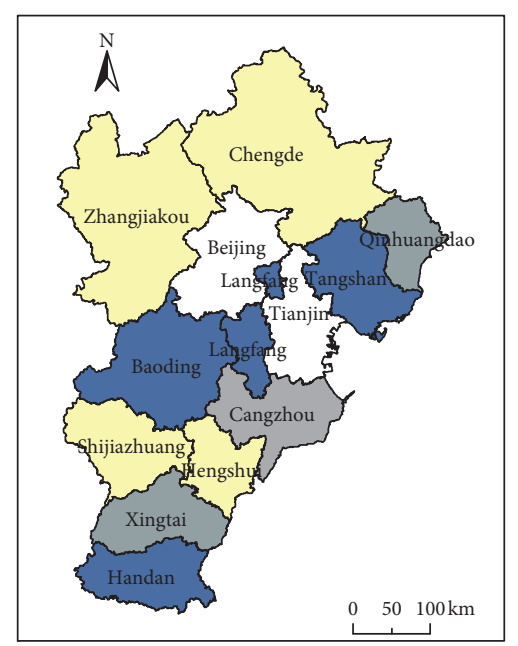

LQ (2014)

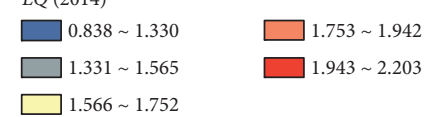

(c)

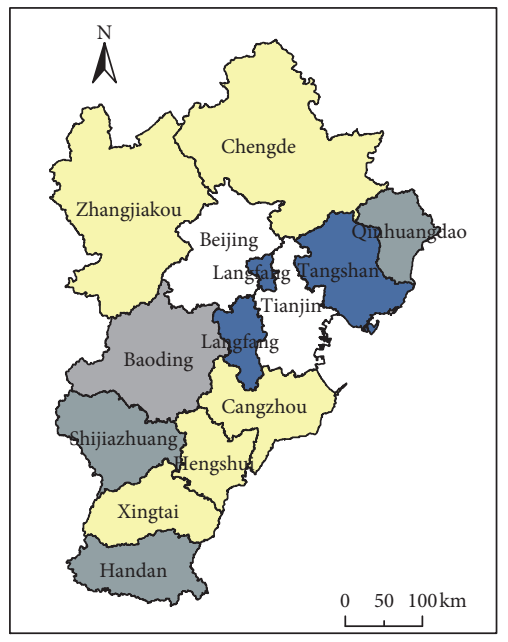

LQ (2017)

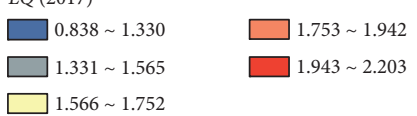

(d) (b)

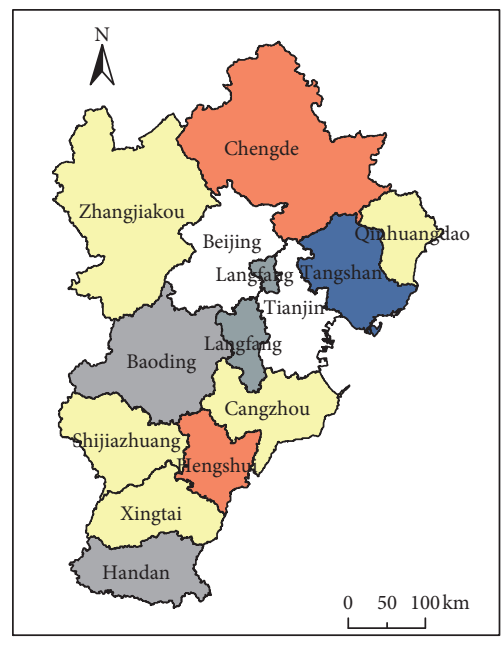

Mean $L Q$

(2008 2017)

$\square .838 \sim 1.330$

$\square 1.331 \sim 1.565$

$\square 1.566 \sim 1.752$

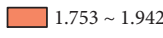

$\square 1.943 \sim 2.203$

(e)

Figure 1: LQ of service industries of Hebei Province, China (2008, 2011, 2014, 2017, and mean).

policies for eligible service enterprises. In 2012, the Hebei Provincial People's Government promulgated Service Industry Development Program of Hebei Province, deciding to further lower the threshold for registration of service enterprises and implement the national preferential tax policy. Meanwhile, the Hebei Provincial People's Government promulgated development programs for specific subsectors of the service sector; for example, Development Outline of Hebei Province on the Conference and Exhibition Industry (2006 to 2010) and Development Program of Hebei Province on Modern Logistics Industry. These policies create a favorable environment for the development of
Hebei's service sector and promote its further specialization. Additionally, Hebei has a large resident population, which provides a huge consumption potential and sufficient labor for the development of the local service industry.

3.2. Spatiotemporal Evolution Characteristics of TFP of the Service Sector. In this study, the TFP of the service sector in each of Hebei's prefecture-level cities is measured using a DEA-Malmquist index model as shown in Figure 2 and as described in Table 1. 


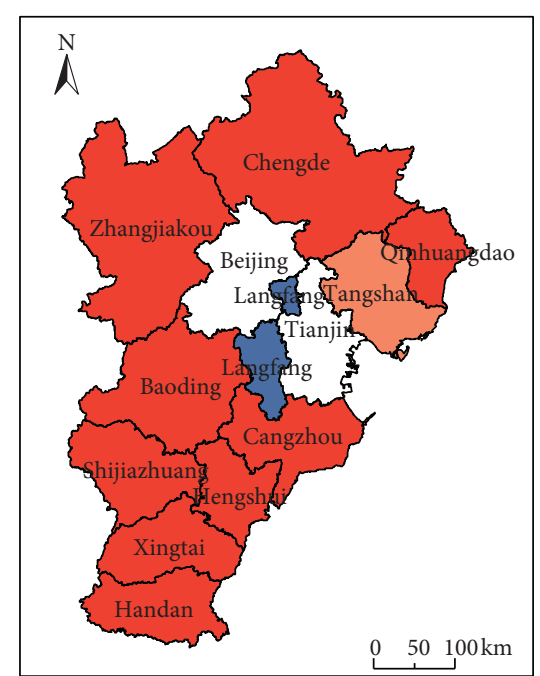

TFP(2008 2009) $\square 0.222 \sim 0.263$
$\square 0.264 \sim 0.370$ $\square 0.371 \sim 0.450$

(a)

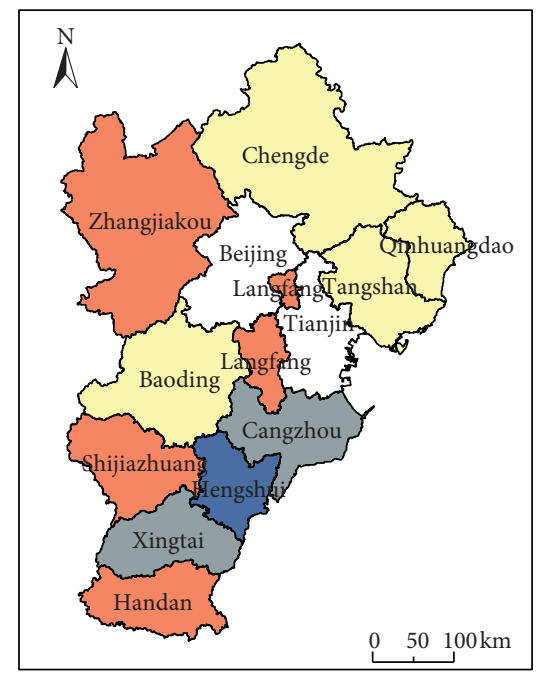

TFP(20014 20015)

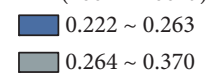

$0.264 \sim 0.370$

$\square 0.371 \sim 0.450$
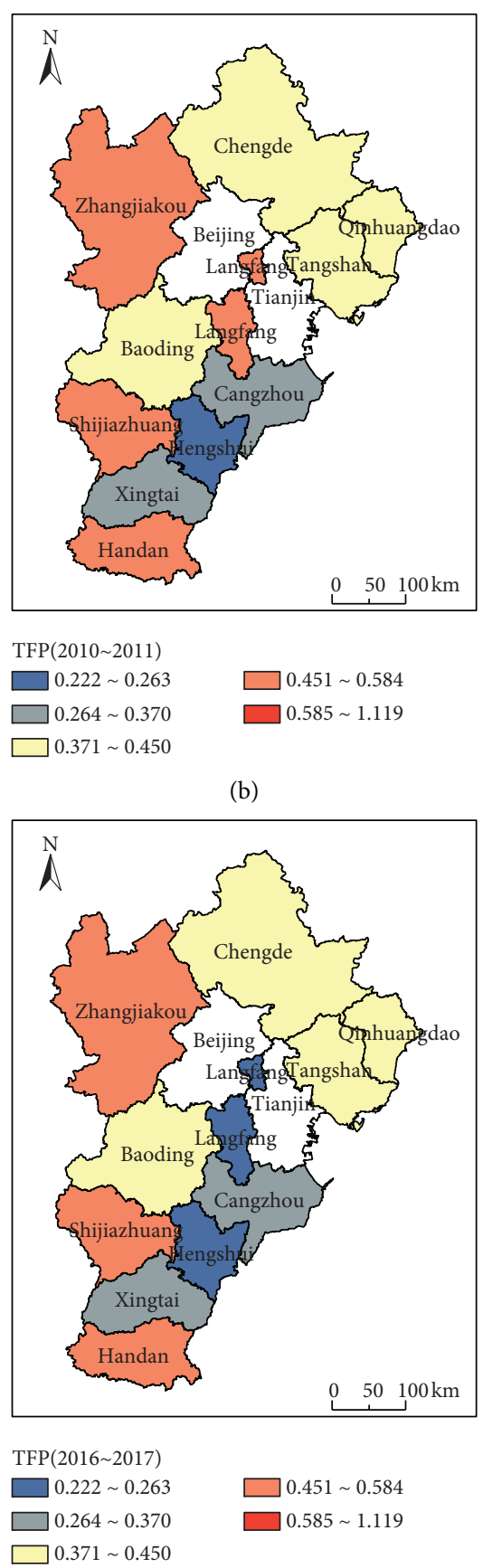

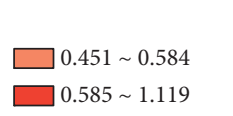

(b)

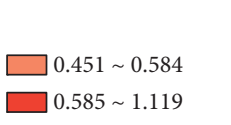

(e)

(d)

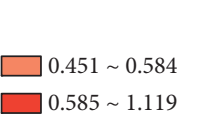

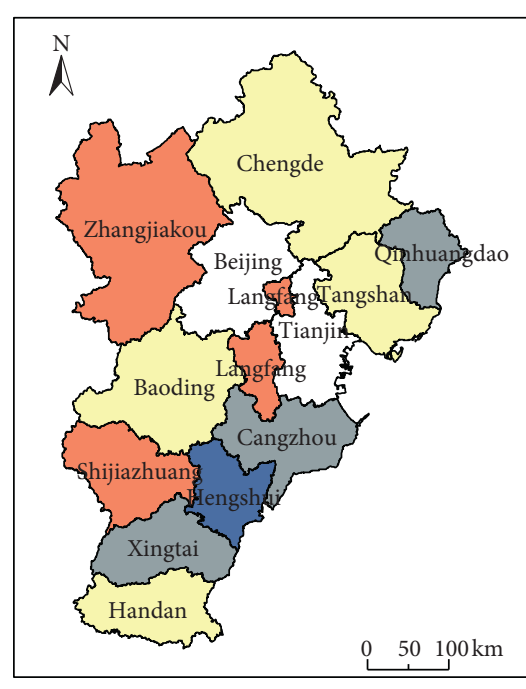

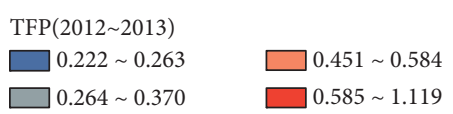

(c)
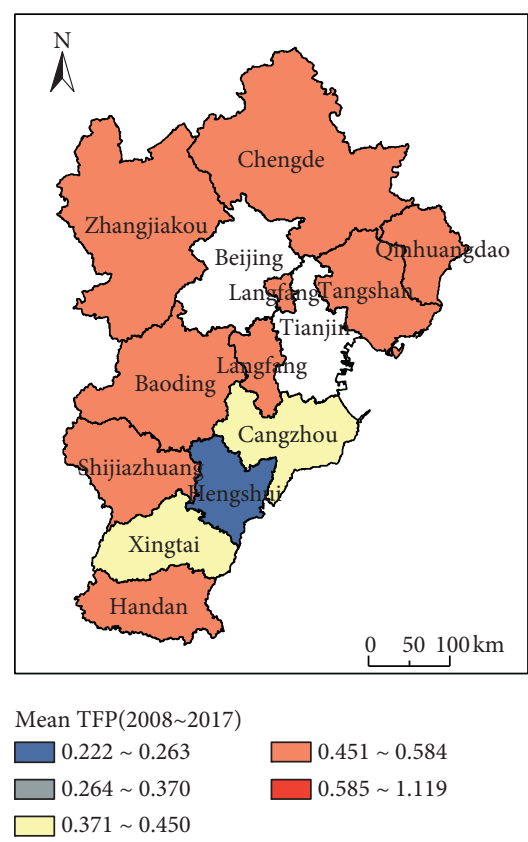

(f)

Figure 2: TFP of service industries of Hebei Province, China (2008 2009, 2010 2011, 2012 2013, 2014 2015, 2016 2017, and mean).

The TFP of the service sector in every such city is greater than 1 (implying that efficiency is effective) in 2008 and 2009 but is lower than 1 (implying efficiency loss) in other years. The breakdown of TFP shows that reduction in TFP can be attributed to reduction in TCH. From 2008 to 2017, average TFP values of the 11 cities are ranked (in descending order) as follows: Shijiazhuang, Zhangjiakou, Langfang, Handan, Tangshan, Chengde, Qinhuangdao, Baoding, Cangzhou, Xingtai, and Hengshui. Spatially, high TFP values are scattered, and low TFP values are concentrated in southern Hebei. While average TFP values are associated with average
$L Q$ values, regions with high or low TFP values are not consistently seen in regions with high or low $L Q$ values. The TFP values of six cities (Shijiazhuang, Chengde, Qinhuangdao, Cangzhou, Handan, and Xingtai) show a $\mathrm{W}$-shaped fluctuation trend (specifically: decline, rise, decline, and rise); the TFP values of three cities (Chengde, Tangshan, and Baoding) show an undulating trend (decline and rise); the TFP values of Langfang show an inverted $\mathrm{N}$-shaped fluctuation trend (decline, rise, and decline); and the TFP values of Hengshui show a valley-shaped variation trend (decline, level, and decline). Except for Shijiazhuang 
TABle 1: PEC, SEC, and TCH of service industries Hebei Province (2008 2017).

\begin{tabular}{|c|c|c|c|c|c|c|c|c|c|c|c|}
\hline & & 2008-2009 & $2009-2010$ & $2010-2011$ & 2011-2012 & 2012-2013 & 2013-2014 & 2014-2015 & 2015-2016 & 2016-2017 & Mean \\
\hline \multirow{3}{*}{ Shijiazhuang } & PEC & 1.000 & 1.000 & 1.000 & 1.000 & 1.000 & 1.000 & 1.000 & 1.000 & 1.000 & 1.000 \\
\hline & SEC & 1.014 & 1.048 & 1.002 & 1.019 & 1.027 & 0.922 & 0.984 & 1.015 & 0.954 & 0.998 \\
\hline & $\mathrm{TCH}$ & 1.069 & 0.511 & 0.531 & 0.514 & 0.520 & 0.540 & 0.524 & 0.509 & 0.544 & 0.585 \\
\hline \multirow{3}{*}{ Chengde } & PEC & 0.947 & 1.057 & 1.224 & 1.296 & 0.736 & 0.876 & 0.788 & 1.147 & 0.776 & 0.983 \\
\hline & SEC & 1.060 & 1.041 & 0.827 & 0.786 & 1.337 & 1.132 & 1.242 & 0.893 & 1.249 & 1.063 \\
\hline & $\mathrm{TCH}$ & 1.069 & 0.381 & 0.406 & 0.400 & 0.403 & 0.407 & 0.404 & 0.397 & 0.418 & 0.476 \\
\hline \multirow{3}{*}{ Qinhuangdao } & PEC & 0.982 & 0.979 & 0.885 & 1.022 & 1.015 & 0.997 & 0.979 & 1.010 & 1.002 & 0.986 \\
\hline & SEC & 1.031 & 1.032 & 1.055 & 0.996 & 0.997 & 0.991 & 1.012 & 1.009 & 0.993 & 1.013 \\
\hline & $\mathrm{TCH}$ & 1.069 & 0.480 & 0.489 & 0.457 & 0.463 & 0.477 & 0.479 & 0.467 & 0.500 & 0.542 \\
\hline \multirow{3}{*}{ Zhangjiakou } & PEC & 1.000 & 1.000 & 1.000 & 1.000 & 1.000 & 1.000 & 1.000 & 1.000 & 1.000 & 1.000 \\
\hline & SEC & 1.030 & 1.172 & 1.020 & 0.993 & 0.992 & 0.997 & 1.013 & 1.003 & 1.004 & 1.025 \\
\hline & $\mathrm{TCH}$ & 1.069 & 0.422 & 0.428 & 0.414 & 0.415 & 0.426 & 0.430 & 0.421 & 0.446 & 0.450 \\
\hline \multirow{3}{*}{ Tangshan } & PEC & 1.000 & 1.000 & 1.000 & 1.000 & 1.000 & 1.000 & 1.000 & 1.000 & 1.000 & 1.000 \\
\hline & SEC & 1.000 & 1.000 & 1.000 & 1.000 & 1.000 & 1.000 & 1.000 & 1.000 & 1.000 & 1.000 \\
\hline & $\mathrm{TCH}$ & 1.069 & 0.422 & 0.428 & 0.414 & 0.415 & 0.426 & 0.430 & 0.421 & 0.446 & 0.497 \\
\hline \multirow{3}{*}{ Langfang } & PEC & 0.923 & 1.005 & 0.957 & 0.980 & 1.034 & 1.016 & 0.918 & 0.966 & 0.561 & 0.929 \\
\hline & SEC & 1.065 & 1.024 & 1.032 & 1.011 & 0.991 & 0.982 & 1.039 & 1.026 & 1.014 & 1.020 \\
\hline & $\mathrm{TCH}$ & 1.069 & 0.500 & 0.514 & 0.494 & 0.493 & 0.512 & 0.516 & 0.493 & 0.462 & 0.561 \\
\hline \multirow{3}{*}{ Baoding } & PEC & 1.000 & 1.132 & 1.000 & 1.000 & 1.000 & 1.000 & 1.000 & 1.000 & 1.000 & 1.015 \\
\hline & SEC & 1.011 & 1.005 & 1.012 & 0.985 & 1.016 & 0.967 & 1.046 & 0.989 & 0.994 & 1.003 \\
\hline & $\mathrm{TCH}$ & 1.069 & 0.350 & 0.377 & 0.367 & 0.371 & 0.377 & 0.378 & 0.380 & 0.396 & 0.452 \\
\hline \multirow{3}{*}{ Cangzhou } & PEC & 1.055 & 1.178 & 1.000 & 1.000 & 1.000 & 1.000 & 1.000 & 1.000 & 1.000 & 1.026 \\
\hline & SEC & 0.992 & 1.104 & 1.000 & 1.000 & 1.000 & 1.000 & 1.000 & 1.000 & 1.000 & 1.011 \\
\hline & $\mathrm{TCH}$ & 1.069 & 0.284 & 0.323 & 0.318 & 0.324 & 0.329 & 0.328 & 0.325 & 0.339 & 0.404 \\
\hline \multirow{3}{*}{ Hengshui } & PEC & 1.000 & 1.000 & 1.000 & 1.000 & 1.000 & 1.000 & 1.000 & 1.000 & 1.000 & 1.000 \\
\hline & SEC & 1.005 & 2.273 & 1.000 & 1.000 & 1.000 & 1.000 & 1.000 & 1.000 & 1.000 & 1.142 \\
\hline & $\mathrm{TCH}$ & 1.069 & 0.150 & 0.227 & 0.222 & 0.223 & 0.230 & 0.230 & 0.230 & 0.241 & 0.314 \\
\hline \multirow{3}{*}{ Xingtai } & PEC & 0.981 & 1.172 & 1.030 & 0.996 & 0.991 & 0.983 & 1.014 & 0.991 & 1.012 & 1.019 \\
\hline & SEC & 1.027 & 1.153 & 0.978 & 1.002 & 1.006 & 1.015 & 0.990 & 1.007 & 0.992 & 1.019 \\
\hline & $\mathrm{TCH}$ & 1.069 & 0.273 & 0.321 & 0.316 & 0.319 & 0.322 & 0.323 & 0.320 & 0.336 & 0.400 \\
\hline \multirow{3}{*}{ Handan } & PEC & 1.004 & 1.005 & 1.029 & 0.960 & 1.001 & 0.982 & 0.992 & 1.055 & 0.985 & 1.001 \\
\hline & SEC & 1.002 & 1.002 & 0.996 & 1.009 & 1.000 & 1.002 & 1.002 & 0.991 & 1.002 & 1.001 \\
\hline & $\mathrm{TCH}$ & 1.069 & 0.454 & 0.462 & 0.452 & 0.446 & 0.458 & 0.458 & 0.448 & 0.486 & 0.526 \\
\hline
\end{tabular}

and Zhangjiakou, the TFP values of the cities fluctuate significantly: there is a difference of more than 0.5 between their TFP values from 2009 to 2010 and those from 2016 to 2017. Spatially, the cities with only small fluctuations of TFP are all in Western Hebei, whereas cities with a significant fluctuation of TFP are mostly in Eastern Hebei. The overall inefficiency of Hebei's service sector may be due to insufficient innovation and a low urbanization level. In 2008, the number of Hebei's granted patents was 5,496, accounting for $1.3 \%$ of China's total granted patents, and Hebei's urbanization rate was $41.9 \%$ (below China's average urbanization rate of $45.7 \%$ ). In 2017, the number of Hebei's granted patents was 35,348 , accounting for $1.9 \%$ of China's total granted patents, and Hebei's urbanization rate was $55 \%$, still below China's average urbanization rate. On one hand, insufficient innovation fails to provide technical support for an improvement in TFP; on the other hand, the low urbanization level fails to provide sufficient demand impetus to the improvement of service sector efficiency.

\section{Relationship between Agglomeration and Efficiency of Hebei's Service Industry}

4.1. Constructing PVAR Models. The interactive relationship between industry agglomeration and industry efficiency is a complex issue. Most previous studies on this topic discuss their relationship through panel models and often ignore the possible endogeneity problem. Panel vector autoregression (PVAR) models combine the advantages of panel models and vector autoregression models while considering all variables as endogenous variables, thereby effectively dealing with the endogeneity problem of the model variables. As such, PVAR models have no requirements for the length of the data's time sequence [44]. Therefore, PVAR models are used in this study. To fully mirror the relationship between service industry agglomeration and efficiency, three $P V A R$ models (specifically, the PVAR models between $L Q$ and TEC, $L Q$ and PEC, and $L Q$ and TCH) were constructed. The model settings are as follows: 


$$
\begin{aligned}
& Y_{l t \_i t}=\gamma_{0}+\sum_{j=1}^{k} \gamma_{j} Y_{l t \_i t-j}+\alpha_{\mathrm{i}}+\beta_{\mathrm{t}}+\varepsilon_{\mathrm{it}}, \\
& Y_{l p \_i t}=\gamma_{0}+\sum_{j=1}^{k} \gamma_{j} Y_{l p \_i t-j}+\alpha_{\mathrm{i}}+\beta_{\mathrm{t}}+\varepsilon_{\mathrm{it}}, \\
& Y_{l c \_i t}=\gamma_{0}+\sum_{j=1}^{k} \gamma_{j} Y_{l l_{\imath \_} i t-j}+\alpha_{\mathrm{i}}+\beta_{\mathrm{t}}+\varepsilon_{\mathrm{it}},
\end{aligned}
$$

where $Y_{l \_\_i t}, Y_{l p \_i t}$, and $Y_{l c_{-} i t}$ denote the two-dimensional column vectors between $L Q$ and TEC, between $L Q$ and PEC, and between $L Q$ and $\mathrm{TCH}$, respectively; $i$ denotes a specific city, $t$ denotes a specific year, and $\gamma_{0}$ denotes the intercept term. $\alpha_{i}, \beta_{t}$, and $\varepsilon_{i t}$ denote the individual effect, time effect, and random disturbance term, respectively.

Before the PVAR models were constructed, it was necessary to ensure the stationarity of each variable. To ensure robustness of test results, panel unit root tests were conducted using four methods (i.e., the IPS method for heterogeneous root test, LLC method for homogenous root test, HT method for short panel test, and PP-Fisher method). Additionally, $L Q$, TEC, PEC, and TCH were, respectively, logarithmized as lnlq, lntec, lnpec, and lntch, thereby eliminating the heteroscedasticity of variables. The results of Table 2 show that, under the four different test methods, all four variables reject the null hypothesis about nonstationarity of variables at the $1 \%$ significance level. This indicates that the stationarity of variables is high enough to meet the prerequisite for PVAR modeling.

\subsection{Determining the Optimal Lag Order and Testing the} Stationarity of Each Model. To ensure the validity of model regression, it was necessary to determine the optimal lag order of each model and test the stationarity of each model. The optimal lag order of each model was determined based on the principle of information criterion minimizing. Orders where the minimum values of MBIC, MAIC, and MQIC criteria were located were optimal lag orders. The results of Table 3 show that the optimal lag orders of the three models are all 1 . Stationary PVAR models require that all characteristic roots of the adjoint matrix fall into a unit circle, which is to say that the modulus values of characteristic roots should all be less than 1 . Test results show that all three models are stationary.

4.3. GMM Regression Results and Granger Causality Test. After the optimal lag order of each model was determined, preliminary regression analysis was conducted on the three models using the generalized method of moments (GMM). The regression analysis results are shown in Table 4.

Table 4 shows that, in Model (1), when Inlq (service industry agglomeration) is the dependent variable, the coefficient of self-influence of lnlq in the $1^{\text {st }}$ lag period is 0.393 at the $1 \%$ significant level. TEC has no significant influence on service industry agglomeration. Evidently, service industry agglomeration can promote its own development and primarily relies on its own development momentum. When
TEC is used as a dependent variable, the coefficients of influence of lnlq and TEC in the $1^{\text {st }}$ lag period on TEC are, respectively, 0.557 and -0.272 , and are significant at $1 \%$ and $5 \%$ levels. Evidently, during the study period, service industry agglomeration in the $1^{\text {st }}$ lag period appears to improve TEC significantly, whereas TEC in the $1^{\text {st }}$ lag period has a certain inhibitory effect on itself. In Model (2), lnlq (service industry agglomeration) and PEC, respectively, are used as dependent variables. The lnlq in the $1^{\text {st }}$ lag period has a revelatory positive influence on these two dependent variables at the $1 \%$ significance level, the coefficients of such influence being 0.407 and 0.313 , respectively. The PEC in the $1^{\text {st }}$ lag period has no significant effect on the lnlq or itself. In Model (3), when lnlq is used as a dependent variable, the lnlq in the $1^{\text {st }}$ lag period has a positive influence on itself, whereas $\mathrm{TCH}$ in the $1^{\text {st }}$ lag period has no significant influence on lnlq. When TCH is used as a dependent variable, the lnlq in the $1^{\text {st }}$ lag period has a negative influence on $\mathrm{TCH}$ at the $1 \%$ significance level. To summarize, service industry agglomeration serves to improve the technical efficiency and pure technical efficiency but has a certain inhibitory effect on technical change. This may be because the agglomeration of enterprises is beneficial to optimizing internal resource allocation and improving the resource utilization ability and overall management standards. As for the inhibitory effect on technical change, it appears that the agglomeration of enterprises suppresses the $R \& D$ motivation of enterprises; the imitation of innovative products being one reason for it being that innovative products can be easily imitated.

Table 5 shows that, in Models (1) to (3), service sector agglomeration is the Granger cause of TEC, PEC, and TCH, but none of these is the Granger cause of service sector agglomeration. This is consistent with the aforementioned regression results. Evidently, during the study period, service sector agglomeration has a certain influence on service sector efficiency. Specifically, service sector agglomeration serves to improve technical efficiency and pure technical efficiency but has a certain inhibitory effect on TCH. With the Granger causality between variables confirmed, impulse response and variance breakdown on variables can be conducted.

4.4. Impulse Response. The impulse response function can measure the short-term response of other variables in a model to the impact of one standard deviation witnessed by any variable in the model. This means that the function can estimate the degree and influence trend of the impact variable to the response variables. Using the Monte Carlo method, 300 simulations were conducted to obtain the impulse response functions of the three models in 10 periods within the 95\% confidence interval (as shown in Table 6). Rows 1,2, and 3, respectively, show the impulse response results of Models (1), (2), and (3). The first variable denotes the impact variable, and the second variable denotes the response variable; the horizontal axis indicates the number of predicted periods, the vertical axis indicates the degree of response, and the shade area indicates the 95\% confidence interval. 
TABle 2: Panel unit root test.

\begin{tabular}{lcccc}
\hline Variable name & IPS & LLC & HT & PP-Fisher \\
\hline lnlq & $-5.417^{* * *}(0.000)$ & $-9.399^{* * *}(0.000)$ & $-6.598^{* * *}(0.000)$ & $-10.158^{* * *}(0.000)$ \\
lntec & $-3.404^{* * *}(0.000)$ & $-4.714^{* * *}(0.000)$ & $-19.365^{* * *}(0.000)$ & $-3.833^{* * *}(0.000)$ \\
lnpec & $-4.518^{* * *}(0.000)$ & $-4.201^{* * *}(0.000)$ & $-18.357^{* * *}(0.000)$ & $-3.348^{* * *}(0.000)$ \\
lntch & $-30.849^{* * *}(0.000)$ & $-1.751^{* *}(0.040)$ & $-11.578^{* * *}(0.000)$ & $-20.794^{* * *}(0.000)$ \\
\hline
\end{tabular}

Note: ${ }^{*}, * *$, and ${ }^{* * *}$ represent significant levels of $10 \%, 5 \%$, and $1 \%$, respectively.

TABLE 3: The test results of MBIC, MAIC, and MQIC.

\begin{tabular}{|c|c|c|c|c|c|c|c|c|c|}
\hline \multirow{2}{*}{ Lag order } & \multicolumn{3}{|c|}{ Model (1) } & \multicolumn{3}{|c|}{ Model (2) } & \multicolumn{3}{|c|}{ Model (3) } \\
\hline & MBIC & MAIC & MQIC & MBIC & MAIC & MQIC & MBIC & MAIC & MQIC \\
\hline 1 & -38.751 & -14.807 & -22.863 & -38.907 & -14.963 & -23.019 & -34.530 & -10.585 & -18.642 \\
\hline 2 & -32.320 & -14.362 & -20.404 & -26.779 & -8.821 & -14.863 & -28.602 & -10.644 & -16.686 \\
\hline 3 & -20.933 & -8.961 & -12.989 & -20.205 & -8.233 & -12.262 & -16.913 & -4.941 & -8.970 \\
\hline 4 & -7.437 & -1.451 & -3.465 & -7.973 & -1.987 & -4.002 & -6.500 & -5.514 & -2.528 \\
\hline
\end{tabular}

TABLE 4: GMM estimation results of PVAR model.

\begin{tabular}{|c|c|c|c|c|c|c|}
\hline \multirow{2}{*}{ Variable } & \multicolumn{2}{|c|}{ Model (1) } & \multicolumn{2}{|c|}{ Model (2) } & \multicolumn{2}{|c|}{ Model (3) } \\
\hline & Lnlq & lntec & Lnlq & lnpec & Lnlq & Lntch \\
\hline L1. Lnlq & $0.393^{* * *}(0.008)$ & $0.558^{* * *}(0.003)$ & $0.407^{* * *}(0.002)$ & $0.313^{* * *}(0.008)$ & $0.289^{* *}(0.027)$ & $-0.245^{* * *}(0.000)$ \\
\hline L1. Lntec & $0.063(0.529)$ & $-0.272^{* *}(0.020)$ & & & & \\
\hline L1. Lnpec & & & $0.065(0.458)$ & $-0.183(0.534)$ & & \\
\hline L1. Lntch & & & & & $0.074(0.311)$ & $-0.026(0.521)$ \\
\hline
\end{tabular}

Note: L1 represents a lag period; ${ }^{*},{ }^{* *}$, and ${ }^{* * *}$ represent significant levels of $10 \%, 5 \%$, and $1 \%$, respectively.

TABLE 5: Granger causality test results between variables.

\begin{tabular}{|c|c|c|c|c|c|}
\hline Variable & Null hypothesis & Lag order & $\mathrm{chi}^{2}$ & $P$ & Conclusion \\
\hline $\operatorname{lnlq} \longrightarrow \ln t e c$ & lnlq is not Granger cause of lntec & 1 & 8.576 & $0.003^{* * *}$ & Reject the null hypothesis \\
\hline $\ln t e c \longrightarrow \operatorname{lnlq}$ & lntec is not Granger cause of lnlq & 1 & 0.396 & 0.529 & Accept the null hypothesis \\
\hline $\operatorname{lnlq} \longrightarrow \operatorname{lnpec}$ & lnlq is not Granger cause of lnpec & 1 & 6.940 & $0.008^{* * *}$ & Reject the null hypothesis \\
\hline $\operatorname{lnpec} \longrightarrow \operatorname{lnlq}$ & lnpec is not Granger cause of lnlq & 1 & 0.550 & 0.458 & Accept the null hypothesis \\
\hline $\operatorname{lnlq} \longrightarrow \ln t \mathrm{ch}$ & lnlq is not Granger cause of lntch & 1 & 19.245 & $0.000^{* * *}$ & Reject the null hypothesis \\
\hline $\operatorname{lntch} \longrightarrow \operatorname{lnlq}$ & lntch is not Granger cause of lnlq & 1 & 1.026 & 0.311 & Accept the null hypothesis \\
\hline
\end{tabular}

Note: ${ }^{*},{ }^{* *}$, and ${ }^{* * *}$ represent significant levels of $10 \%, 5 \%$, and $1 \%$, respectively.

TABLE 6: Impulse response function results.

\begin{tabular}{lccccccccccc}
\hline Model & Period & 1 & 2 & 3 & 4 & 5 & 6 & 7 & 8 & 9 \\
\hline \multirow{4}{*}{ Model(1) } & lnlq:Inlq & 0.100 & 0.045 & 0.023 & 0.010 & 0.000 & 0.000 & 0.000 & 0.000 & 0.000 & 0.000 \\
& Inlq:Intec & 0.050 & 0.044 & 0.010 & 0.005 & 0.002 & 0.000 & 0.000 & 0.000 & 0.000 & 0.000 \\
& lntec:Inlq & 0.000 & 0.005 & 0.000 & 0.000 & 0.000 & 0.000 & 0.000 & 0.000 & 0.000 & 0.000 \\
& lntec:Intec & 0.070 & -0.02 & 0.010 & 0.000 & 0.000 & 0.000 & 0.000 & 0.000 & 0.000 & 0.000 \\
\hline \multirow{4}{*}{ Model(2) } & lnlq:Inlq & 0.100 & 0.045 & 0.020 & 0.000 & 0.000 & 0.000 & 0.000 & 0.000 & 0.000 & 0.000 \\
& lnlq:Inpec & 0.025 & 0.026 & 0.008 & 0.000 & 0.000 & 0.000 & 0.000 & 0.000 & 0.000 & 0.000 \\
& lnpec:Inlq & 0.000 & 0.003 & 0.000 & 0.000 & 0.000 & 0.000 & 0.000 & 0.000 & 0.000 & 0.000 \\
& lnpec:Inpec & 0.070 & -0.020 & 0.010 & 0.000 & 0.000 & 0.000 & 0.000 & 0.000 & 0.000 & 0.000 \\
\hline \multirow{5}{*}{ Model(3) } & lnlq:Inlq & 0.100 & 0.025 & 0.005 & 0.000 & 0.000 & 0.000 & 0.000 & 0.000 & 0.000 & 0.000 \\
& Inlq:Intch & -0.017 & -0.027 & -0.007 & -0.002 & 0.000 & 0.000 & 0.000 & 0.000 & 0.000 & 0.000 \\
& Intch:Inlq & 0.000 & 0.003 & 0.000 & 0.000 & 0.000 & 0.000 & 0.000 & 0.000 & 0.000 & 0.000 \\
& lntch:Intec & 0.045 & -0.001 & 0.000 & 0.000 & 0.000 & 0.000 & 0.000 & 0.000 & 0.000 & 0.000 \\
\hline
\end{tabular}

Table 6 shows that, in Models (1) to (3), the degree of self-influence of service industry agglomeration reaches its peak of 0.1 in the $1^{\text {st }}$ period, then decreases dramatically (followed by a continuous slowdown in the decrease), changes slightly, and tends to zero after the $4^{\text {th }}$ period. This shows that the agglomeration of Hebei's service sector follows a self-reinforcing mechanism and is highly self-reliant. In Model (1), service sector agglomeration is shown to 
have a positive influence on technical efficiency, implying that agglomeration improves TEC, with the improvement effect decreasing as the number of periods increases. In Model (2), service sector agglomeration also has a positive influence on PEC. Unlike the influence on TEC, the influence on PEC reaches an extreme in the $2^{\text {nd }}$ period and then continues to decrease and gradually tends to reach zero. In Model (3), service sector agglomeration has a negative influence on TCH. The negative influence reaches an extreme in the $2^{\text {nd }}$ period, then decreases continuously, and finally reaches zero. Study results show that service sector agglomeration still plays an important role in improving technical efficiency and pure technical efficiency and it has a certain inhibitory effect on further improvement in TCH. As the number of periods increases, both effects-improvement and inhibitory-tend to weaken. The degree and influence trend of TEC, PEC, and TCH on service industry agglomeration are similar across the three models. Specifically, the degree of influence of service sector efficiency on service sector agglomeration reaches its maximum (positive) in the $2^{\text {nd }}$ period and then decreases in subsequent periods. Evidently, the improvement in service sector efficiency has a certain positive influence on the sector's agglomeration. As shown by the impulse response function diagrams of TEC, PEC, and TCH with respect to themselves, the influence of TEC on itself shows an undulating decline; specifically, its influence is maximized in the $1^{\text {st }}$ period, declines to a negative value in the $2^{\text {nd }}$ period, and increases undulatingly and tends to reach zero in subsequent periods. This shows that technical efficiency is also positively influenced by its development momentum, but this positive influence does not continue. The influence of PEC on itself is maximized (positive) in the $1^{\text {st }}$ period, is minimized (negative) in the $2^{\text {nd }}$ period, and increases gradually to be positive in the $3^{\text {rd }}$ and subsequent periods. The influence of $\mathrm{TCH}$ on itself is maximized in the $1^{\text {st }}$ period, decreases dramatically to a negative value in the $2^{\text {nd }}$ period, and increases slowly and tends to reach zero in subsequent periods. Evidently, TCH relies on its development momentum only at an early stage; compared with TEC and PEC, TCH has little influence on itself. This may be because new technologies or products that enterprises develop at a high cost generate high profits at early stage, so enterprises are motivated to further upgrade their technologies and products; however, the regulatory environment may not provide a watertight intellectual property and patent protection system, so enterprises are not sufficiently motivated to pursue continuous technological improvement, resulting in a substantial reduction in $\mathrm{TCH}$.

4.5. Variance Decomposition. Variance decomposition of the PVAR models can reveal the error contribution ratio of each model, variable to the forecast variance of any other single variable, thereby presenting the relationship between variables more intuitively. Table 7 shows the variance decomposition results of the three models.

Table 7 shows that, in Model (1), the contribution of service sector agglomeration to itself is $100 \%$ in the $1^{\text {st }}$ period and still as high as $99.8 \%$ in the $10^{\text {th }}$ period. In Models (2)
TABLE 7: Variance decomposition results of each variable.

\begin{tabular}{lccccccc}
\hline \multirow{2}{*}{ Variable } & \multirow{3}{*}{ Period } & \multicolumn{2}{c}{ Model (1) } & \multicolumn{2}{c}{ Model (2) } & \multicolumn{2}{c}{ Model (3) } \\
& & lnlq & lntec & lnlq & lnpec & lnlq & lntch \\
\hline lnlq & 1 & 1 & 0.273 & 1 & 0.115 & 1 & 0.093 \\
lnlq & 5 & 0.998 & 0.386 & 0.998 & 0.224 & 0.999 & 0.281 \\
lnlq & 10 & 0.998 & 0.387 & 0.998 & 0.224 & 0.999 & 0.281 \\
lntec & 1 & & 0.728 & & & & \\
lntec & 5 & 0.003 & 0.614 & & & & \\
lntec & 10 & 0.003 & 0.613 & & & & \\
lnpec & 1 & & & & 0.885 & & \\
lnpec & 5 & & & 0.002 & 0.776 & & \\
lnpec & 10 & & & 0.002 & 0.776 & & \\
lntch & 1 & & & & & & 0.907 \\
lntch & 5 & & & & & 0.001 & 0.719 \\
lntch & 10 & & & & & 0.001 & 0.719 \\
\hline
\end{tabular}

and (3), variance decomposition results of the service sector reveal that the explanatory power of service sector agglomeration on itself is $100 \%$ in the $1^{\text {st }}$ period and more than $99 \%$ in the $10^{\text {th }}$ period. Evidently, the agglomeration of Hebei's service sector is primarily reliant on its own development momentum, with the consequent centripetal force further promoting the agglomeration of enterprises, thereby producing a causal cycle of agglomeration. The variance decomposition results of TEC reveal the following: (1) the contribution ratio of TEC to itself is $72.8 \%$ in the $1^{\text {st }}$ period and then decreases gradually to $61.3 \%$ in the $10^{\text {th }}$ period; (2) the contribution ratio of service industry agglomeration to TEC tends to increase gradually from $27.3 \%$ in the $1^{\text {st }}$ period to $38.7 \%$ in the $10^{\text {th }}$ period. Evidently, the improvement in TEC has a certain reliance on itself, but the degree of self-reliance decreases over time. However, the degree of influence of service sector agglomeration increases. This may be because the agglomeration of enterprises is beneficial in attracting superior production factors and reducing infrastructure construction costs, with close social network ties improving the efficiency of resource allocation within enterprise clusters. In Model (2), variance decomposition results reveal that the variation trend of pure technical efficiency is similar to that of technical efficiency: the influence of pure technical efficiency is decreasing, and the influence of service sector agglomeration is increasing. This may be because service sector agglomeration produces a professional talent pool and brings about knowledge spillover, thereby improving the ability of enterprises to innovate. In Model (3), the contribution of PEC to itself is $90.7 \%$ in the $1^{\text {st }}$ period and $71.9 \%$ in the $10^{\text {th }}$ period; the contribution of service industry agglomeration to PEC is $9.3 \%$ in the $1^{\text {st }}$ period and $28.1 \%$ in the $10^{\text {th }}$ period. At the initial stage of service industry agglomeration, new products can easily be plagiarized or imitated by similar enterprises, so enterprises are not always willing to constantly develop new technologies or products. As the number of periods increases, patent protection systems become increasingly robust, so enterprises are then more inclined to gain a market advantage by developing new technologies. 


\section{Discussion and Conclusion}

5.1. Discussion. China's economic development has entered a relatively stable stage-the "new normal"-and its labor cost advantage is disappearing. In this context, the traditional rapid economic growth model, which relies heavily on increasing factor inputs, is difficult to sustain. At this stage of economic growth, it is of vital importance to improve TFP. TFP is influenced by a variety of factors, especially industry agglomeration. This study discusses the spatial evolution characteristics of Hebei's service sector agglomeration and TFP from 2008 to 2017 and empirically tests the dynamic relationship between them. This study examines the spatial structure and efficiency of Hebei's service sector and presents an extensive survey of its development. In doing so, it provides a certain theoretical support for improving the TFP of Hebei's service sector. Usually, TFP is considered as an approach to technical change, and improvement in TFP is a complex and dynamic process [45]. This study discusses the influence of a single factor (i.e., sector agglomeration) on TFP. Subsequent research on this topic should analyze other important influences on TFP (e.g., urbanization level and industrial structure) in depth as well as the contribution of different factors. This study shows that the agglomeration effect in the service sector does not only promote economic growth but also has a crowding effect and an inhibitory effect on economic growth at a certain stage of development or under certain circumstances, depending on spatiotemporal scales and socioeconomic conditions. On a provincial scale, this study discusses the spatial evolution of service sector agglomeration and TFP as well as the interactive relationship between them. Subsequent studies should examine the agglomeration of different sectors and their TFP on a city or county scale.

5.2. Conclusions. This study measures the degree of agglomeration and efficiency of the services sectors of Hebei's cities from 2008 to 2017 and analyzes the interactive relationship between them using PVAR models. The findings are summarized as follows: (1) from 2008 to 2017, the service sectors of Hebei's cities are highly agglomerated and enjoy the advantage of a high degree of specialization, with agglomeration decreasing slightly over time. The $L Q$ values of the 11 cities are ranked (in descending order) as follows: Hengshui, Chengde, Zhangjiakou, Shijiazhuang, Cangzhou, Qinhuangdao, Xingtai, Langfang, Baoding, Handan, and Tangshan. (2) From 2008 to 2017, the service sector efficiency is pervasively low in Hebei's cities and is lower than 1 in most years, meaning that efficiency is low and there is severe efficiency loss; the average efficiency values of the 11 cities are ranked (in descending order) as follows: Shijiazhuang, Zhangjiakou, Langfang, Handan, Tangshan, Chengde, Qinhuangdao, Baoding, Cangzhou, Xingtai, and Hengshu. Thus, the cities with a high degree of service sector agglomeration do not consistently have a high sector efficiency. (3) GMM regression results and impulse response functions reveal that service sector agglomeration has its own self-promoting effect. Also, service industry agglomeration serves to improve TEC and PEC, and it has an inhibitory effect on TCH. (4)
Variance decomposition results reveal that efficiency is influenced by itself more significantly than by service sector agglomeration; over time, the importance of efficiency to itself decreases marginally, whereas the importance of efficiency to service sector agglomeration increases.

The following policies are recommended: (1) It is necessary to promote a reasonable agglomeration of the service sector and optimize its structure. The concerned authorities should further lower the threshold of market access to the sector, encourage the acquisitions and mergers, and restructure among enterprises, promote the growth of group enterprises, and create a more favorable environment for the sector. Additionally, it is necessary to emphasize functional complementarity between service enterprises, prevent blind cluster development, and ensure overall rationality and coherence in the sector. (2) It is necessary to improve the service sector efficiency and reduce the efficiency loss. Enterprises should actively communicate with and cooperate with research institutions and colleges, increase $R \& D$ investment, and apply advanced technologies and management ideas to improve enterprise efficiency. The concerned authorities should eliminate the barriers to free movement of various factors (e.g., manpower and capital) and promote the free movement of production factors across Hebei, thereby improving service sector efficiency. (3) It is necessary to develop a robust intellectual property protection system and strengthen the innovation consciousness of enterprises. The concerned authorities should further improve relevant laws and regulations, create a fair and reasonable competitive environment, and protect the innovative spirit of enterprises, so that innovation becomes a key driver for the service sector.

\section{Data Availability}

The primary data used to support the findings of this study are available from the author upon request.

\section{Conflicts of Interest}

There are no conflicts of interest among authors.

\section{Acknowledgments}

This study acknowledges the support of the NSFC (National Natural Science Foundation of China) under Project Numbers (41771131 and 41877523); the Beijing Municipal Natural Science Foundation under Project Number (8182018); and the Premium Funding Project for Academic Human Resources Development in Beijing Union University under Project Number (BPHR2020AS02).

\section{References}

[1] R. M. Solow, "A contribution to the theory of economic growth," The Quarterly Journal of Economics, vol. 70, no. 1, pp. 65-94, 1956.

[2] I. Kataryniuk and J. Martínez-Martín, "TFP growth and commodity prices in emerging economies," Emerging Markets Finance and Trade, vol. 55, no. 10, pp. 2211-2229, 2019. 
[3] A. Otsuka, "Regional determinants of total factor productivity in Japan: stochastic frontier analysis," The Annals of Regional Science, vol. 58, no. 3, pp. 579-596, 2017.

[4] D. Herzer and J. Donaubauer, "The long-run effect of foreign direct investment on total factor productivity in developing countries: a panel cointegration analysis," Empirical Economics, vol. 54, no. 2, pp. 309-342, 2018.

[5] R. Harris and J. Moffat, "Plant-level determinants of total factor productivity in Great Britain, 1997-2008," Journal of Productivity Analysis, vol. 44, no. 1, pp. 1-20, 2015.

[6] J. G. Liu, G. P. Li, J. T. Zhang, and T. S. Sun, "Spatial distribution and its affecting factors of economy efficiency and total factor productivity in China: 1990-2009," Acta Geographica Sinica, vol. 67, no. 8, pp. 1069-1084, 2012, in Chinese.

[7] R. Li, Q. Guo, D. Wu, H. Yin, H. Zhang, and T. Zhu, "Spatial characteristics of development efficiency for urban tourism in eastern China: a case study of six coastal urban agglomerations," Journal of Geographical Sciences, vol. 24, no. 6, pp. 1175-1197, 2014.

[8] B. Q. Lin and R. P. Tan, "Economic agglomeration and green economy efficiency in China," Economic Research Journal, vol. 54, no. 2, pp. 119-132, 2019, in Chinese.

[9] L. Zou, C. Zhou, L. Che, and B. Wang, "Spatio-temporal evolution and influencing factors of urban green development efficiency in China," Journal of Geographical Sciences, vol. 30, no. 5, pp. 724-742, 2020.

[10] F. Qiu, Y. Chen, J. Tan, J. Liu, Z. Zheng, and X. Zhang, "Spatial-temporal heterogeneity of green development efficiency and its influencing factors in growing metropolitan area: a case study for the Xuzhou metropolitan area," Chinese Geographical Science, vol. 30, no. 2, pp. 352-365, 2020.

[11] N. Najkar, M. R. Kohansal, and M. Ghorbani, "Impact of industrial agglomeration on productivity: evidence from Iran's food industry," Chinese Geographical Science, vol. 30, no. 2, pp. 309-323, 2020.

[12] G. C. G. Rosero, "Growth agglomeration effects in spatially interdependent Latin American regions," SSRN Electronic Journal, vol. 1611, 2015.

[13] M. Fujita and J. F. Thisse, "Does geographical agglomeration foster economic growth? and who gains and loses from it?" Japanese Economic Review, vol. 54, no. 2, pp. 121-145, 2010.

[14] W. Yu, "Creative industries agglomeration and industrial efficiency in China," Growth and Change, vol. 49, no. 4, pp. 677-695, 2018.

[15] J. J. Wang, F. H. Hang, and C. Yu, "The analysis on dynamic effect of service agglomeratton on productivity-evidence from 261 cities in China," Economic Theory and Business Management, vol. 3, pp. 48-58, 2014, in Chinese.

[16] R. Silva, "Competition and demand effects of geographic distance to rivals," The Service Industries Journal, vol. 36, no. 1-2, pp. 37-57, 2016.

[17] J. G. Williamson and G. Jeffrey, "Regional inequality and the process of national development: a description of the patterns," Economic Development and Cultural Change, vol. 13, no. 4, pp. 1-84, 1965.

[18] C. Bordei, "Clusters-sources of economic growth in Europe," Sea: Practical Application of Science, vol. 4, no. 1, pp. 141-148, 2016.

[19] H. Nagy, B. Illes, J. Kaposzta, and I. Donnik, "Clusters and concentration of businesses in regions of some European countries as tools for economic development," Engineering for Rural Development-International Scientific Conference, vol. 24, pp. 248-253, 2017.
[20] M. Andersson, J. P. Larsson, and J. Wernberg, “The economic microgeography of diversity and specialization externalities firm-level evidence from Swedish cities," Research Policy, vol. 48, no. 6, pp. 1385-1398, 2019.

[21] S. J. Huang and C. Zhang, "The influences of the agglomeration of producer services on the urban productivity: from the perspective of industry heterogeneity," Urban Development Studies, vol. 23, no. 3, pp. 118-124, 2016, in Chinese.

[22] K. Zhou, H. Liu, and Q. Wang, "The impact of economic agglomeration on water pollutant emissions from the perspective of spatial spillover effects," Journal of Geographical Sciences, vol. 29, no. 12, pp. 2015-2030, 2019.

[23] C. L. Qin and Q. Q. Yang, "The effect of HSR on the spatial pattern dynamics of producer service," Economic Geography, vol. 37, no. 2, pp. 90-97, 2017, in Chinese.

[24] L. Que and C. L. Fang, "Comprehensive assessment on the spatial agglomeration of producer services in Beijing," Geographical Research, vol. 32, no. 1, pp. 99-110, 2013, in Chinese.

[25] E. G. Harris and D. E. Fleming, "The productive service employee: personality, stress, satisfaction and performance," Journal of Services Marketing, vol. 31, no. 6, pp. 499-511, 2017.

[26] Z. S. Ding, Y. Wang, Z. Y. Sang, Y. R. Li, X. Y. Song, and C. J. Xia, "A study on the spatial agglomeration characteristics of township productive service industry-taking Changshu city, Jiangsu province as an example," Scientia Geographica Sinica, vol. 34, no. 8, pp. 938-945, 2014, in Chinese.

[27] N. Corrocher and L. Cusmano, "The "KIBS engine" of regional innovation systems: empirical evidence from European regions," Regional Studies, vol. 48, no. 7, pp. 1212-1226, 2014.

[28] B. Kamp and E. Sisti, "Assessing the relationship between ICT services and the manufacturing industry from a meso-economice perspective: insights from the Basque country," $E u$ ropean Review of Service Economics, vol. 2, no. 6, pp. 123-151, 2018.

[29] M. Wyrwich, "New KIBS on the bloc: the role of local manufacturing for start-up activity in knowledge-intensive business services," Regional Studies, vol. 53, no. 3, pp. 320329, 2019.

[30] D. Q. Xue, S. S. Wan, B. B. Ma, and R. Y. Chen, "A study on the spatial agglomeration of cultural industry in Xi'an based on the urban functional pattern," Scientia Geographica Sinica, vol. 39, no. 5, pp. 750-760, 2019, in Chinese.

[31] O. C. Boiteux and R. Guillain, "Changes in the intrametropolitan location of producer services in France (1978-1997): do information technologies promote a more dispersed spatial pattern?" Urban Geography, vol. 25, no. 6, pp. 550-578, 2004.

[32] J. M. Li, T. S. Sun, and W. Z. Zhang, "Spatial cluster characteristics and modes of producer services in China," Scientia Geographica Sinica, vol. 34, no. 4, pp. 385-393, 2014, in Chinese.

[33] M. E. Coll, C. J. Arauzo, and M. A. Moreno, “Agglomeration of creative industries: an intra-metropolitan analysis for Barcelona," Papers in Regional Science, vol. 98, no. 1, pp. 409-431, 2019.

[34] B. Desmarchelier, F. Djellal, and F. Gallouj, "Knowledge intensive business services and long term growth," Structural Change and Economic Dynamics, vol. 25, pp. 188-205, 2013.

[35] Z. M. Li and Z. X. Fan, "Analysis of agglomeration and temporal spatial evolution of high and new technology industries in Poyang Lakeeco-economic zone," RevistaDe La FacultadDe Ingenieria, vol. 32, no. 12, pp. 740-745, 2017. 
[36] J. Yao and G. Changchun, "An empirical study on spatial agglomeration of creative industry and firm performance," R\&D Management, vol. 30, no. 2, pp. 61-70, 2018.

[37] H. X. Chen and G. P. Li, "Spatial characteristics and economic impact of producer services agglomeration in China," Economic Geography, vol. 36, no. 8, pp. 113-119, 2016, in Chinese.

[38] C. C. Williams and I. A. Horodnic, "Extent and distribution of unregistered employment in the service industries in Europe," The Service Industries Journal, vol. 38, no. 11-12, pp. 856-874, 2018.

[39] G. Y. Ren and T. Y. Jiang, "The agglomeration and reasons of knowledge-intensive business service in Yangtze river delta region," Economic Geography, vol. 35, no. 5, pp. 85-91, 2015, in Chinese.

[40] X. D. Wang, X. Q. Liu, T. Pei, and Z. B. Wang, "Potential evaluation of urban land intensive use in Beijing-Tianjin-Hebei region based on measurement of technical efficiency," Acta Geographica Sinica, vol. 74, no. 9, pp. 1853-1865, 2019, in Chinese.

[41] J. G. Liu and W. Z. Zhang, "The spatial spillover effects of regional total factor productivity in China," Scientia Geographica Sinica, vol. 34, no. 5, pp. 522-530, 2014, in Chinese.

[42] T. T. Yu, Y. X. Song, F. L. Hao, and W. G. Wang, "The inequality of economic efficiency and space pattern evolution in Jilin province," Scientia Geographica Sinica, vol. 36, no. 7, pp. 1066-1072, 2016, in Chinese.

[43] R. E. Hall and C. I. Jones, "Why do some countries produce so much more output per worker than others?" The Quarterly Journal of Economics, vol. 114, no. 1, pp. 83-116, 1999.

[44] Z. L. Han, J. Z. Zhang, T. B. Liu, F. Peng, and J. Q. Zhang, "The spatiotemporal characteristics and development trend forecast of innovative TFP growth in China's three northeastern provinces," Scientia Geographica Sinica, vol. 37, no. 2, pp. 161-171, 2017, in Chinese.

[45] X. L. Huang and J. G. Liu, "Regional economic efficiency and its influencing factors of Beijing-Tianjin-Hebei metropolitans in China based on a heterogeneity stochastic frontier model," Chinese Geographical Science, vol. 30, no. 1, pp. 30-44, 2020. 